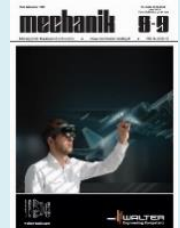

Authors: Agnieszka Skoczylas, Kazimierz Zaleski

Title of article: „Wpływ parametrów technologicznych w procesie frezowania stali EZ6NCT25 na wybrane wskaźniki skrawalności” (,Influence of the cutting parameters on the selected machinability indicators in the milling of steel EZ6NCT25”)

Mechanik, Vol. 91, No. 8-9 (2018): pages 772-774

DOI: https://doi.org/10.17814/mechanik.2018.8-9.130

\title{
Influence of the cutting parameters on the selected machinability indicators in the milling of steel EZ6NCT25
}

\author{
Wpływ parametrów technologicznych w procesie frezowania stali \\ EZ6NCT25 na wybrane wskaźniki skrawalności
}

\author{
AGNIESZKA SKOCZYLAS \\ KAZIMIERZ ZALESKI *
}

The paper reports results of an investigation of the cutting torque and surface roughness in the face milling of EZ6NCT25 steel. Classified as stainless steel, EZ6NCT25 is effectively used in the aviation and shipbuilding industries. This steel grade is used for producing elements such as turbine blades and combustion chamber assemblies. Experimental tests were performed with the use of full-carbide monolithic tools with the diameter of $d=12 \mathrm{~mm}$. The tests were conducted at variable technological parameters. It has been observed that that cutting torque and amplitude cutting torque depend on machining conditions, and also, although to a lesser extent the surface roughness.

KEYWORDS: stainless steel EZ6NCT25, face milling, cutting torque, surface roughness

Stainless steels, which include EZ6NCT25 steel, are considered to be hard-to-cut materials [2]. They are characterized by high ductility and tendency to deformation, which contributes to the increase of cutting forces.

For example, after drilling stainless austenitic steel UNS32100 there was a significant increase in microhardness of the surface layer, which depending on the technological parameters ranged from $30 \%$ to $90 \%$ [1]. Due to the high tendency to adhesion during the cutting of austenitic stainless steels, a build-up is created, which adversely affects the roughness of the treated surface. Small conductivity and heat capacity of these steels cause intensive heating of cutting tools, which reduces their durability [2, 5].

Stainless steel EZ6NCT25 is high alloy (alloy constituents make up more than $40 \%$ of the chemical composition) austenitic steel, which is characterized by very bad machinability. On the other hand, this material exhibits good properties as a structural material, e.g. high strength

\footnotetext{
dr inż. Agnieszka Skoczylas (a.skoczylas@pollub.pl), dr hab. inż. Kazimierz Zaleski, prof. PL (k.zaleski@pollub.pl), Politechnika Lubelska, Wydział Mechaniczny, Katedra Podstaw Inżynierii Produkcji
}

and corrosion resistance at high temperature. Tests of tribological properties of this steel at elevated temperature confirmed that with the temperature rise to the value of approx. $300{ }^{\circ} \mathrm{C}$, material consumption decreases during sliding friction when using a lubricant containing molybdenum disulphide nanoparticles. After exceeding this temperature, the consumption increased, while at a temperature of approx. $500{ }^{\circ} \mathrm{C}$ it was equal to the consumption at ambient temperature [7].

The properties of EZ6NCT25 steel determine its application in the manufacture of components exposed to high loads, operating in corrosive environments and at high temperatures. This steel is mainly used in the aerospace industry, for example for the manufacture of fasteners and fasteners and aircraft engine parts.

The previous tests of machinability of the EZ6NCT25 steel were mainly carried out during turning machining. The results of investigations of the cutting dynamics of this steel were presented in $[3,4]$. It was found that the rolling course of this steel can be monitored by recursive analysis.

In the paper [6], the results of comparative research on the influence of the depth of cut on the components of the total cutting force and displacement of the workpiece during turning of C45 steel, titanium alloy TI6AI4V and steel EZ6NCT25 are quoted. The signals recorded from the measurements were analyzed using the delayed coordinates method, used to study non-linear phenomena.

The aim of the authors of this article was to assess the impact of cutting parameters in the process of milling steel EZ6NCT25 on the momentum of cutting, reactive force and roughness of the treated surface.

\section{Research methodology}

The tests used samples of steel EZ6NCT25, whose chemical composition is shown in the table.

Face milling concurrent was carried out on the vertical milling center Avia VMC $800 \mathrm{HS}$, located at the Department of Production Engineering at the Lublin University of Technology. As a tool, carbide cutters of diameter $d=12$ $\mathrm{mm}$ from Kennametal (marked with the symbol UJDE1200A6AS) were used. 
TABLE. Chemical composition of EZ6NCT25 steel [7]

\begin{tabular}{|c|c|c|c|c|c|c|c|}
\hline \multicolumn{7}{|c|}{ Elements contents, \% } \\
\hline $\mathrm{C}$ & $\mathrm{Ni}$ & $\mathrm{Cr}$ & $\mathrm{Mo}$ & $\mathrm{Ti}$ & $\mathrm{V}$ & $\mathrm{B}$ & $\mathrm{Fe}$ \\
\hline 0,07 & 27,0 & 15,5 & 1,2 & 2,0 & 0,3 & 0,005 & $\begin{array}{c}\text { the } \\
\text { rest }\end{array}$ \\
\hline
\end{tabular}

The machining process, with abundant cooling of the Mobile Cut cooling liquid lubricant, was carried out with the following technological parameters:

- cutting speed $v_{\mathrm{c}}=20 \div 50 \mathrm{~m} / \mathrm{min}$,

- feed per tooth $f_{z}=0.05 \div 0.2 \mathrm{~mm} /$ blade,

- cutting depth $a_{p}=0.2 \div 0.5 \mathrm{~mm}$,

- milling width $a_{e}=7.5 \mathrm{~mm}$.

The cutting torque measurement $M_{c}$ was carried out using a Kistler 9125A rotary force measuring device, which together with the 52377A1/A2 amplifier and the DAQ 5697A data acquisition module was a measuring circuit.

Surface roughness measurements were made with the Hommel-Etamic T8000RC 120-140 device.

\section{Results}

Based on the time courses of the cutting momentum (fig. 1 ), charts showing the effect of cutting process parameters on the maximum value of momentum $M_{c}$ and torque amplitude were made.

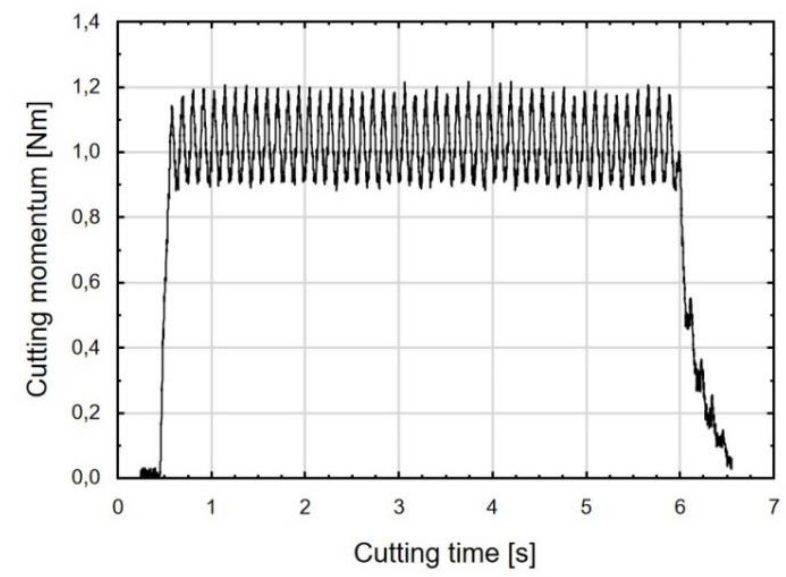

1. Time course of the cutting momentum $\left(v_{c}=20 \mathrm{~m} / \mathrm{min}\right.$, $a_{p}=0.3 \mathrm{~mm}, f_{z}=0.1 \mathrm{~mm} /$ blade)

Fig. 2 shows the influence of the cutting depth $a_{p}$ on the cutting momentum $M_{c}$ and its amplitude. An increase in the depth of cut by $150 \%$ increased the value of the maximum cutting torque by $123 \%$ and the amplitude of the cutting torque by $153 \%$.

Also, the increase in feed per blade $f_{z}$ caused - as expected - an increase in the cutting momentum (fig. 3), however this dependence is of a different nature than the relationship shown in fig. 2 . The increase in the cutting momentum in the feed function is progressive (in the feed range $0.05 \div 0.1 \mathrm{~mm} / \mathrm{blade}$, the $M_{\mathrm{c}}$ growth is $61 \%$, and in the feed range $0.1 \div 0.2 \mathrm{~mm} /$ blade $-38 \%$ ), which is consistent with the rule known for other materials that with the increase of the thickness of the machined layer, the cutting resistance. However, the increase in feed does not affect the amplitude of the cutting momentum (the changes in the amplitude of $M_{c}$ seen in fig. 3 are within the error limits).

Fig. 4 shows the influence of the cutting speed $v_{c}$ on the value of the cutting momentum $M_{c}$ and its amplitude. There is a clear drop in both the momentum and its amplitude, especially at a lower cutting speed. In the examined range of cutting speeds, the cutting momentum was reduced by $52 \%$ and the torque amplitude by $66 \%$.

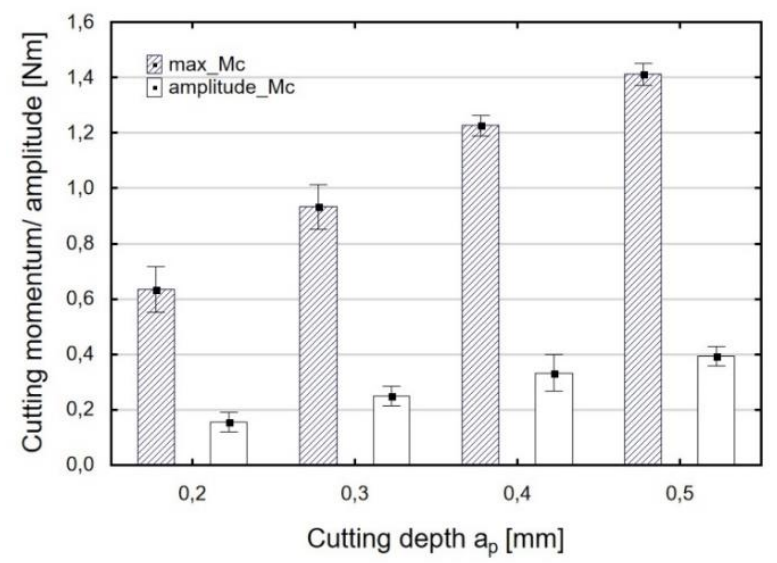

Fig. 2. Influence of the cutting depth $a_{p}$ on the cutting momentum $M_{c}$ and the amplitude of the momentum $\left(v_{c}=30 \mathrm{~m} / \mathrm{min}, f_{z}=0.1\right.$ $\mathrm{mm} / \mathrm{blade}$ )

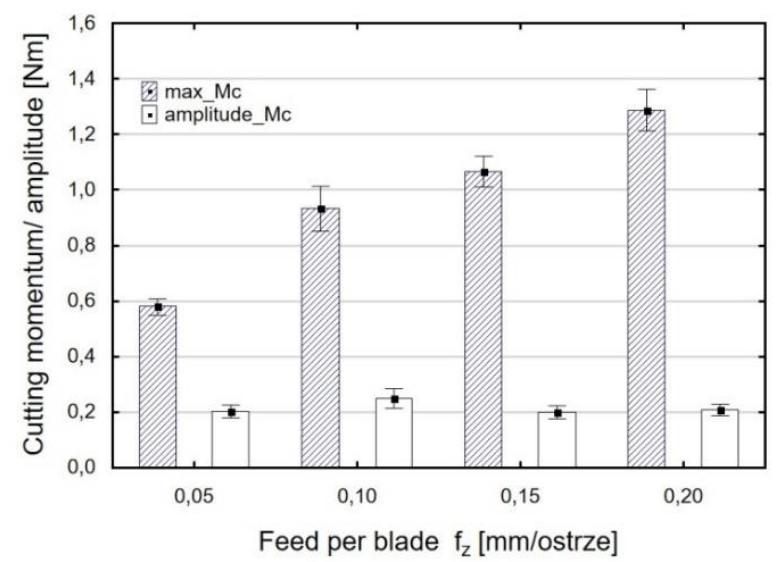

Fig

3. Influence of feed on the blade $f_{z}$ at the cutting momentum $M_{c}$ and the amplitude of the momentum $\left(v_{\mathrm{c}}=30 \mathrm{~m} / \mathrm{min}, a_{p}=0.3 \mathrm{~mm}\right)$

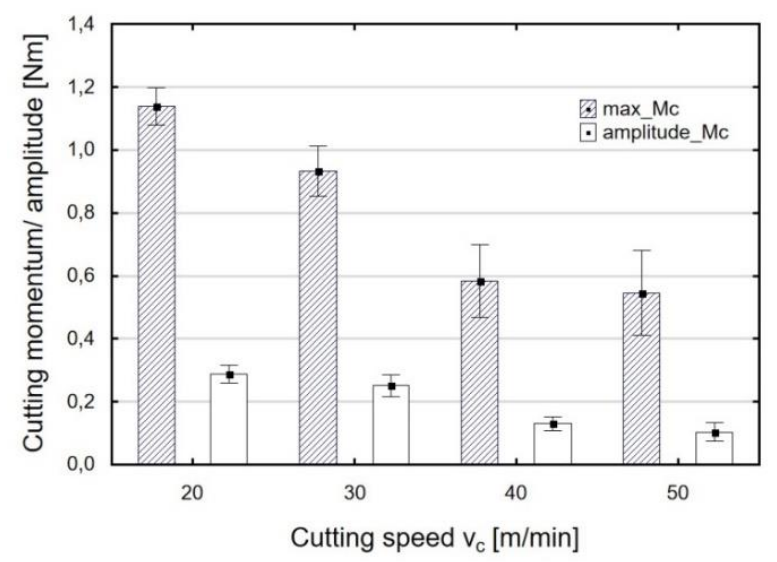

Fig.

4. Influence of cutting speed $v_{\mathrm{c}}$ on the cutting momentum $M_{\mathrm{c}}$ and torque amplitude $\left(f_{z}=0.1 \mathrm{~mm} / \mathrm{blade}, a_{p}=0.3 \mathrm{~mm}\right)$

Results of the research on the influence of technological parameters of milling steel EZ6NCT25 on $R a$ and $R z$ parameters of surface roughness are presented in figs. 5-7. With an increase in the depth of $a_{p}$ cutting, there is a slight increase in the roughness of the surface treated (with a $2.5 \mathrm{x}$ increase in the depth of cut, the $R z$ parameter increased by $19.5 \%$ - fig. 5). This can be explained by the increase in the amplitude of the cutting moment, resulting in greater vibration of the cutter.

As expected, the increase in feed rate increases surface roughness, but it is relatively small (fig. 6). With four feed increases, the $R z$ parameter increased by $63 \%$ and the $R a$ parameter increased by $64 \%$. Considering that the feed increase translates directly into an increase in machine 
machining time, it should be considered reasonable to use higher feed rates.

As the cutting speed increased, the surface roughness decreased (fig. 7). At a two and a half times higher cutting speed, the $R a$ parameter was reduced by $25 \%$ and $R z$ parameter by $32 \%$. It should be assumed that the decrease in cutting speed is related to the reduction of the cutting moment, in particular the torque amplitude, which translates into improved tool stability. The drop in surface roughness parameters $R a$ and $R z$ can also be caused by the limitation of the increase effect when the cutting speed $v_{\mathrm{c}}$ is increased

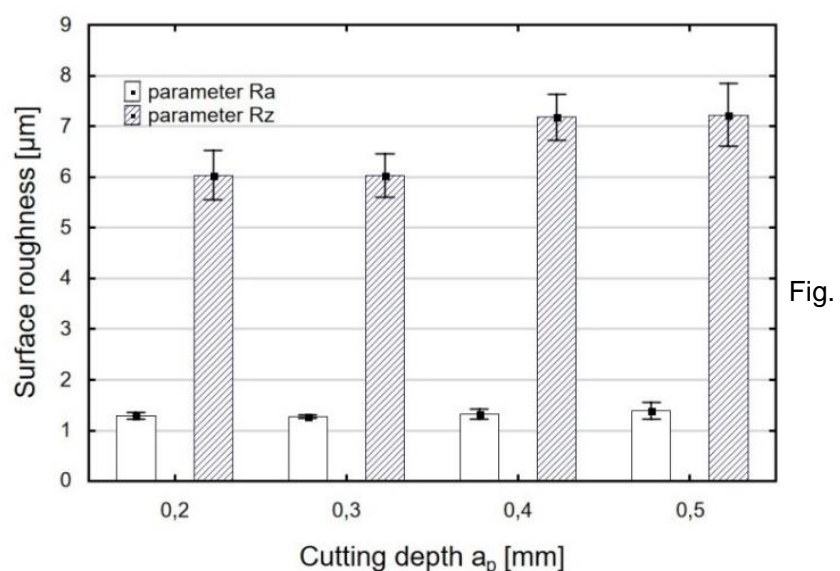

5. Influence of the cutting depth $a_{p}$ on the roughness parameters $R a$ and $R z\left(v_{\mathrm{c}}=30 \mathrm{~m} / \mathrm{min}, f_{\mathrm{z}}=0.1 \mathrm{~mm} /\right.$ blade $)$

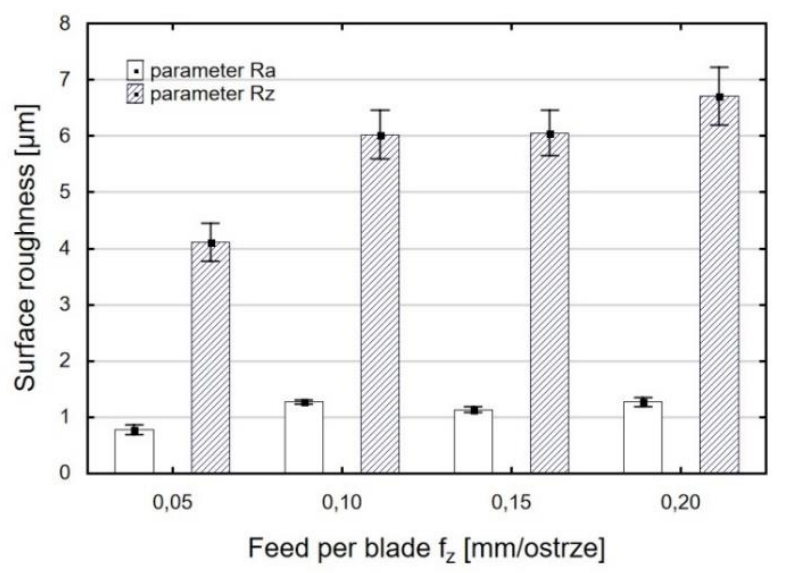

Fig.

6. Influence of feed on the blade $f_{z}$ on roughness parameters $R a$ and $R z\left(v_{\mathrm{c}}=30 \mathrm{~m} / \mathrm{min}, a_{\mathrm{p}}=0.3 \mathrm{~mm}\right)$

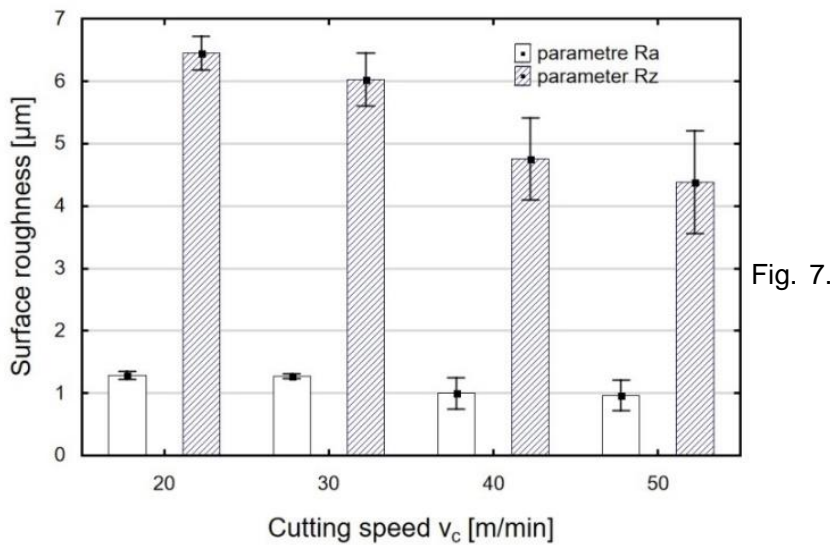

Influence of cutting speed $v_{c}$ on roughness parameters $R a$ and $R z$ $\left(f_{z}=0.1 \mathrm{~mm} /\right.$ blade, $a_{\mathrm{p}}=0.3 \mathrm{~mm}$

\section{Conclusions}

The study investigated the influence of technological parameters of milling stainless steel EZ6NCT25 on the cutting momentum and parameters $R a$ and $R z$ of surface roughness. The depth of cut value was adopted in the range corresponding to the finishing machining. Cutting speeds were assumed to be relatively small to avoid rapid wear of the milling cutters, which would undoubtedly affect the results of the measurements (preliminary tests carried out during milling trials with a higher cutting speed showed that there were clear signs of wear of the blades after a short machining time). The technological parameters of milling have a much greater impact on the cutting momentum both its maximum value and the amplitude - than on the surface roughness. A relatively small surface roughness was obtained $(R a=0.78 \div 1.39 \mu \mathrm{m})$, which confirms the desirability of milling - as finishing work - of EZ6NCT25 steel items with a uniform carbide burr milling cutter. The feed increase (in the tested range) only slightly affected the roughness of the surface, and therefore a feed rate of $0.15 \div 0.2 \mathrm{~mm} /$ blade may be recommended. In order to determine the recommended cutting speed, it would be necessary to carry out tests on the durability of the cutter blades.

\section{REFERENCES}

1. Dolinsek $S$. "Work-hardening in the drilling of austenitic stainless steel". Journal of Materials Processing Technology. 133 (2003): pp. 63-70.

2. Grzesik W. „Podstawy skrawania materiałów konstrukcyjnych”. Warszawa: WNT, 2010.

3. Litak G., Polyakov Y.S., Timashev S.F., Rusinek R. "Dynamics of stainless steel turning: Analysis by flicker - noise spectroscopy". Physica A. 392 (2013): pp. 6052-6063.

4. Litak G., Rusinek R. "Dynamics of stainless steel Turing processes by statistical and recurrence analyses". Meccanica. 47 (2012): pp. 1517-1526.

5. Miernik M. „Skrawalność metali. Metody określania i prognozowania". Wrocław: Oficyna Wydawnicza Politechniki Wrocławskiej, 2000.

6. Rusinek R. "Vibrations in cutting process of titanium alloy". Eksploatacja i Niezawodność - Maintenance and Reliability. 3 (2010): pp. 48-55.

7. Wisniewska-Weinert $\mathrm{H}$. "Friction and wear of porous sliding bearings at high temperature. Influence of $\mathrm{MoS}_{2}$ nanoparticle solid lubricant". Powder Metallurgy and Metal Ceramics. 52, 78 (2013): pp. 424-430.

Translation of scientific articles, their computer composition and publishing them on the website www.mechanik.media.pl by original articles in Polish is a task financed from the funds of the Ministry of Science and Higher Education designated for dissemination of science.

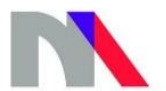

Ministry of Science and Higher Education Republic of Poland 